\title{
The Parkfield Experiment- Capturing What Happens in an Earthquake
}

\begin{abstract}
o better understand what happens on and near a fault before, during, and after an earthquake, the U.S. Geological Survey (USGS) and the California Geological Survey began the Parkfield Earthquake Experiment in the 1980 's. Researchers from the USGS and collaborating institutions have created a dense network of instruments on the San Andreas Fault at Parkfield, California, where moderate earthquakes have occurred at fairly regular intervals. Data from these instruments are revealing the earthquake process in unprecedented detail and will aid in predicting the time and severity of future shocks. The National Science Foundation (NSF) is expanding the Parkfield Experiment by drilling a deep borehole and installing instruments at the actual depths where earthquakes initiate, creating a San Andreas Fault Observatory at Depth (SAFOD).
\end{abstract}

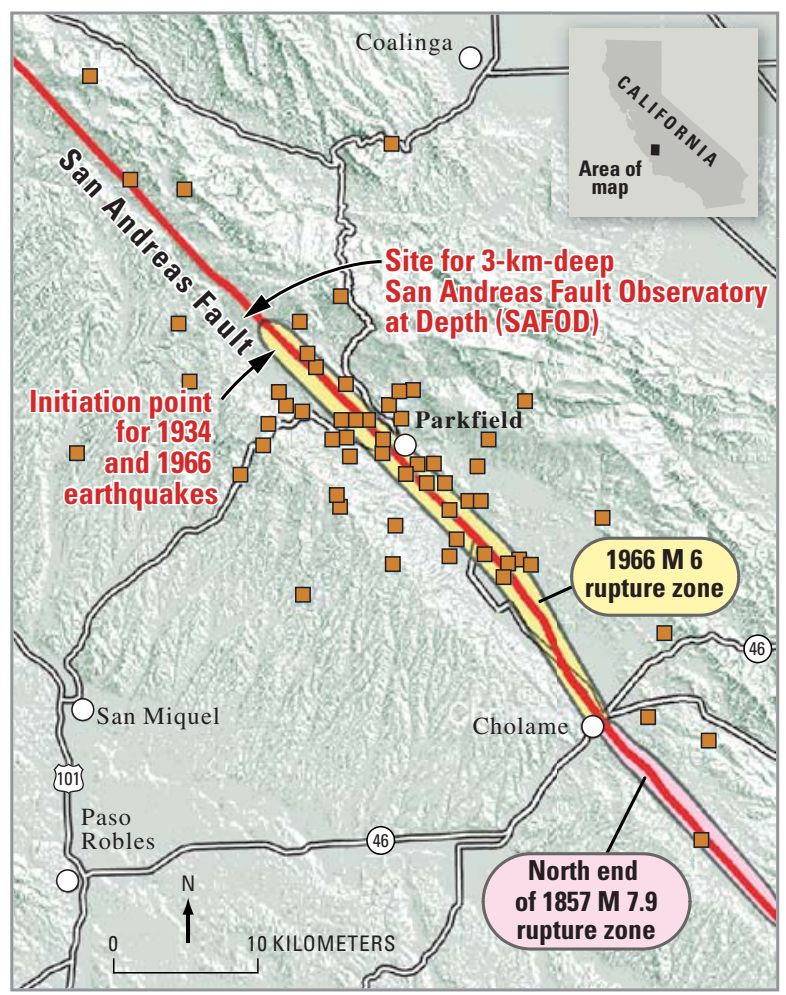

Study area for the Parkfield Earthquake Experiment at Parkfield, California. The Parkfield area is considered an ideal place to study the earthquake process. The San Andreas Fault (red line) last ruptured here in 1966 (yellow zone). A similar rupture in 1857 was a foreshock to the last great earthquake in southern California, the 1857 Fort Tejon magnitude 7.9 event (pink zone). Brown squares represent sites of geophysical monitoring instruments, including seismometers, strainmeters, creepmeters, and global positioning system (GPS) receivers. Drilling for SAFOD began in June 2004 (photo).

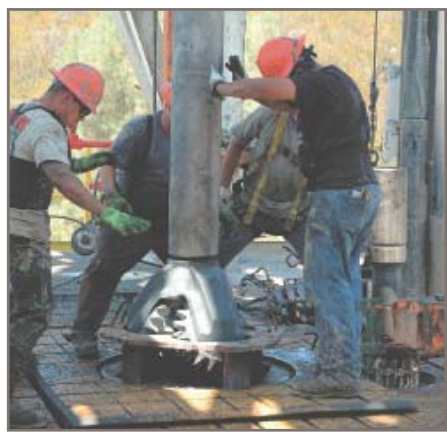

Moderate earthquakes (magnitude about 6) have occurred on the Parkfield section of the San Andreas Fault at fairly regular intervals-in 1857, 1881, 1901, 1922, 1934, and 1966. All these Parkfield earthquakes have struck in the same area-historical seismograms show that at least the 1934 and 1966 shocks initiated at the same point on the fault.

This fairly regular repetition of similar-magnitude earthquakes prompted the U.S. Geological Survey (USGS) in 1985 to forecast the likelihood of another moderate earthquake in the Parkfield region within the next several years. Scientists also recognized that Parkfield was an ideal site to capture the physical processes leading up to and immediately following an earthquake. As a result, the USGS and the California Geological Survey (then the Division of Mines and Geology) placed instruments in the ground at Parkfield to seek methods for making short-term predictions of earthquakes based on precursory events in the preceding hours or days. This initial joint effort developed into the Parkfield Earthquake Experiment.

The goals of the experiment (see box)

MAJOR GOALS OF THE
PARKFIELD EARTHOUAKE EXPERIMENT
- Observe the buildup and release of
stresses on the San Andreas Fault
through multiple earthquake cycles.
- Test the feasibility of short-term earth-
quake prediction.
- Measure near-fault shaking during
earthquake rupture and learn better how
to predict the amplification of shaking
caused by different soil types for improv-
ing building codes and designs.

have both scientific and public safety implications that reach far beyond the rural Parkfield region of central California. To achieve those goals, scientists develop, install, and operate real-time monitoring systems for seismic activity and for various physical and chemical parameters in the rocks, soil, and ground water. Sensitive instruments have been deployed to measure the buildup and release of strain during the earthquake cycle and to precisely record strong ground shaking during the next magnitude 6 earthquake.

Although the anticipated earthquake has not yet occurred, strain continues to accumulate on this section of the fault. Indeed, more energy has now accumulated there since the last magnitude 6 earthquake in 1966 than was released in that quake. Thus, the hazard remains high and the occurrence of another earthquake seems certain. 


\section{Creation of a San Andreas Fault Observatory at Depth (SAFOD)}

Building on more than 15 years of experience from the Parkfield Earthquake Experiment, the National Science Foundation (NSF) is drilling a deep hole in order to install instruments directly within the San Andreas Fault Zone near the initiation point of previous magnitude 6 Parkfield earthquakes. These instruments, set 2 to $3 \mathrm{~km}$ beneath the Earth's surface, will form a San Andreas Fault Observatory at Depth (SAFOD). This project, under the joint leadership of Stanford University and the USGS, will directly reveal, for the first time, the physical and chemical processes controlling earthquake generation on a seismically active fault.

In June 2004, drilling the hole for SAFOD began west of the San Andreas Fault and is using advanced directionaldrilling technology developed by the petroleum industry to angle the hole through the entire fault zone until relatively undisturbed rock is reached on the east side. Fault-zone rocks and fluids will be retrieved for laboratory analyses, and geophysical measurements will be made within the active fault zone. SAFOD's longterm monitoring activities will include detailed observations of small to moderate earthquakes and continuous measurement of rock deformation and other parameters during the earthquake cycle.

SAFOD will provide direct information on the composition and mechanical properties of rocks in the fault zone, the nature of stresses responsible for earthquakes, the role of fluids in controlling faulting and earthquake recurrence, and the physics of earthquake initiation and rupture. By observing quakes "up close," SAFOD will mark a major advance in the pursuit of a rigorous scientific basis for assessing earthquake hazards and predicting earthquakes.

\section{EarthScope and the SAFOD Pilot Hole}

Funding for SAFOD was obtained by NSF as part of an ambitious scientific initiative called EarthScope. The other elements of EarthScope are USArray and the Plate Boundary Observatory (PBO). USArray consists of a large transportable broadband seismic array, augmented by smaller seismic arrays and coordinated with the USGS Advanced National Seismic System. The PBO is a network of deformation sensors for the western United States similar to that deployed at Parkfield. PBO will enhance the USGS's existing network of GPS receivers and strain meters at Parkfield. Support for scientific studies using SAFOD and the other EarthScope facilities will come through programs within NSF, USGS, and other agencies, both in the U.S. and abroad.

In preparation for SAFOD, a 2.2-kmdeep vertical pilot hole was drilled adjacent to the San Andreas Fault at Parkfield in the summer of 2002. This pilot project was developed as a collaborative effort among the International Continental Scientific Drilling Program, NSF, and USGS and is guiding

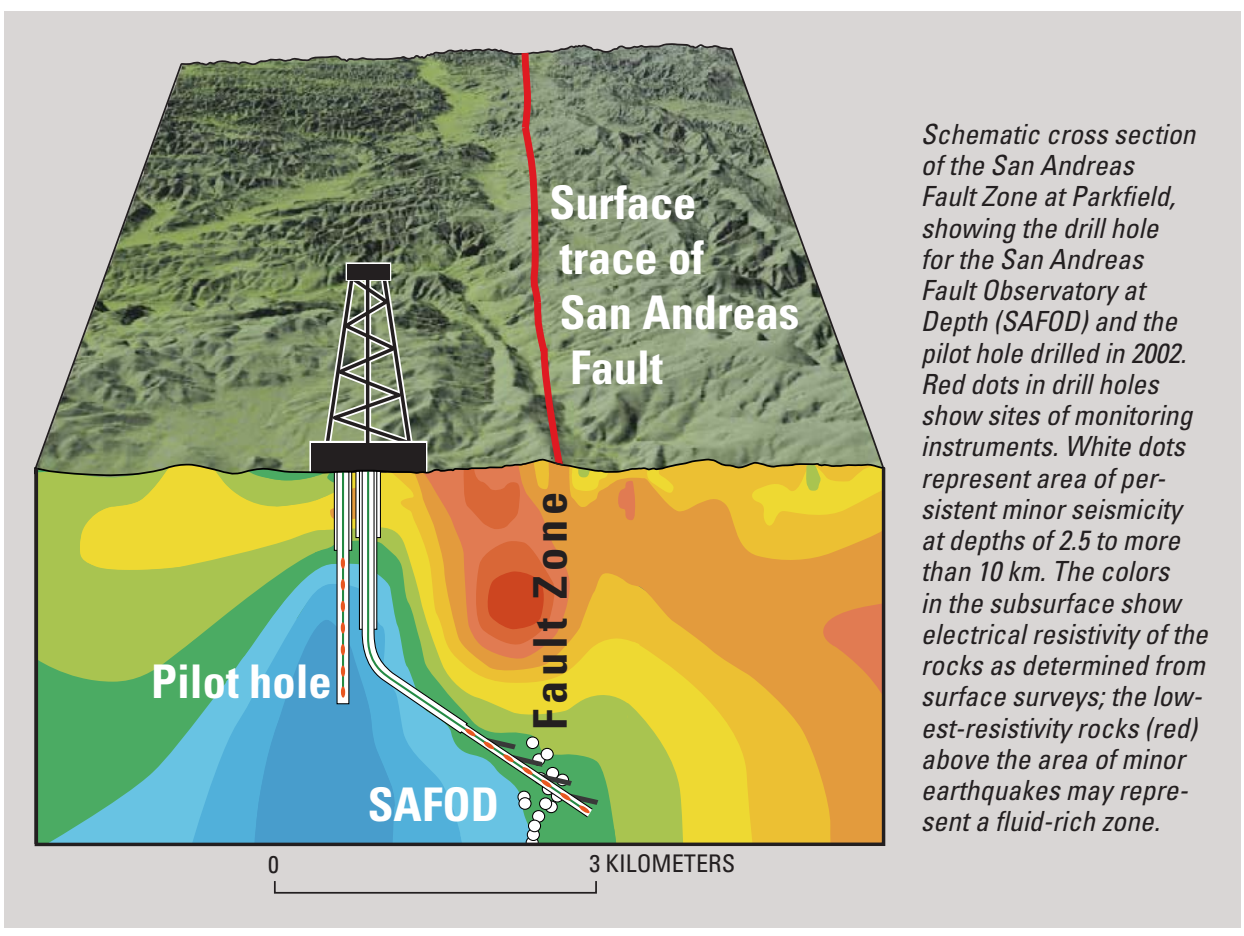

subsequent SAFOD scientific investigations within the active fault zone.

The cooperative efforts of USGS and other scientists in the Parkfield Earthquake Experiment and SAFOD will help achieve a better understanding of what happens on and near a fault during the earthquake cycle and will aid in predicting the time and severity of future quakes. This work is part of the National Earthquake Hazard Reduction Program's ongoing efforts to protect people's lives and property from the earthquakes that are inevitable in California and elsewhere in the United States.

Steve Hickman and John Langbein Edited by

Peter H. Stauffer

Graphic design by Susan Mayfield and Sara Boore

\section{COOPERATING AGENCIES}

California Geological Survey California Office of Emergency Services EarthScope

International Continental Scientific Drilling Program National Science Foundation Stanford University

For more information contact Earthquake Information Office (650) 329-4668

U.S. Geological Survey, Mail Stop 977 345 Middlefield Road Menlo Park, CA 94025 http://quake.usgs.gov/research/parkfield http://www.earthscope.org

This Fact Sheet and any updates to it are available online at:

http://pubs.usgs.gov/fact-sheet/fs049-02/ 